\title{
Por que investir em pesquisa, ciência, tecnologia e inovação (C\&T) no Brasil?
}

\author{
Why invest in research, science, technology and \\ innovation (S\&T) in Brazil?
}

Ana Lúcia Barbosa Góes (1)

Escola Bahiana de Medicina e Saúde Pública, Universidade Federal da Bahia (Salvador). Bahia, Brasil. albgoes@bahiana.edu.br

Desde 2015, temos vistos sucessivos cortes orçamentários para o desenvolvimento da ciência, tecnologia e inovação no Brasil. Esse texto se propõe a analisar o papel das principais agências de fomento à pesquisa (CAPES e CNPq) e as consequências da atual política do governo federal, do apagão no CNPq à fuga de cérebros, no momento presente (e futuro) da ciência e da sociedade brasileiras.

PALAVRAS-CHAVE: Orçamentos; Produção Científica e Tecnológica Nacional; Ciência

Olá, você, leitora e leitor, que reservou alguns minutos do seu tempo para ler essa reflexão.

Vivemos um tempo de polaridades e intolerância à opinião alheia. Principalmente no que diz respeito à política. No entanto, por mais que não gostemos de discutir e debater, a política define 0 rumo da sociedade. Quando não nos envolvemos nas questões políticas, deixamos que outras pessoas decidam a nossa vida por nós.

Você pode estar se perguntando: mas afinal aonde ela quer chegar? Já te explico.
Desde 2016, e mais evidente após as eleições de 2018, fica cada vez mais nítida a tentativa de transformar o estado em estado mínimo, retirando direitos trabalhistas, serviços públicos e privatizando as instituições. Nesse momento, é difícil observar o que tem acontecido nos ministérios e não fazer uma analogia com a pesquisa.

Observamos o Ministério do Meio Ambiente ser assumido por um ministro que, se suspeita, favoreceu desmatamento ilegal, grilagem e a perda de terras pelos povos originários. ${ }^{1}$ Vimos o Ministério da Educação ser assumido por uma sequência de ministros que promoveram sucessivos cortes no orçamento da educação ${ }^{2-7}$, agindo diretamente nas verbas para pesquisa, de Zika-vírus a câncer. Essa situação se agrava se considerarmos o momento de plena pandemia de Covid-19, em que precisamos das instituições públicas de pesquisas e das universidades para produzir vacinas, testes diagnósticos e possíveis tratamentos.,., 7

E nas grandes instituições que promovem, fomentam e divulgam pesquisa, ciência, inovação e tecnologia? O que aconteceu com suas gestões? O que vimos recentemente foi, por um lado, uma pessoa sem expressão e capacidade técnica 
assumindo um espaço importante na $\operatorname{CAPES}^{8,9}$ e, por outro, um apagão de 10 dias nas plataformas do CNPQ que gerou repercussões nefastas para os pesquisadores e as pesquisadoras, para as pesquisas e todo o aparato de fomento por meio de bolsas de pesquisa. $\frac{10,11}{11}$

A CAPES, Coordenação de Aperfeiçoamento de Pessoal de Nível Superior, é um órgão vinculado ao Ministério da Educação (MEC), possui diversos programas de incentivo à pesquisa científica nas mais diversas áreas, como, por exemplo, programas de acesso e divulgação das produções científicas, investimentos na formação de mestres e doutores pesquisadores, programas de cooperação cientifica, entre outros. O foco maior da CAPES é o desenvolvimento científico das pessoas, a formação de recursos humanos para pesquisa.

A CAPES é responsável também por avaliar, a cada quatro anos (avaliação quadrienal), os mais de 4 mil programas de mestrado e doutorado, conferindo aos mesmos qualificações na produção de conhecimento científico e na formação de pesquisadores por meio desses programas. Os parâmetros para a avaliação quadrienal (Qualis Periódicos) têm sido elaborados por membros do Conselho Técnico Científico do Ensino Superior (CTC-ES) e era esperado que no ano de 2021 fosse publicada a avaliação quadrienal de 2017-2020.

Eis que em 10 de setembro de 2021, a CAPES publica a portaria $\mathrm{n}^{\circ} 145$ que define novos parâmetros para o Qualis Periódicos. Em carta aberta, quatro dias após a publicação da portaria, os Coordenadores de Área da CAPES que compõem o CTC-ES como membros titulares manifestam em público preocupação com a condução da avaliação quadrienal, que, segundo eles, desfaz de todo o trabalho construído ao longo de quatro anos junto à Comissão de Acompanhamento do Plano Nacional de Pós-Graduação e avaliação volta a usar instrumentos obsoletos aplicados na avaliação quadrienal passada, sem qualquer avanço.

Ao mesmo tempo em que vemos uma ação (e crise) política interna na CAPES, a publicação dessa portaria levou o Ministério Publico do Rio de Janeiro (MR-RJ) a judicializar o processo de avaliação quadrienal da CAPES, determinando sua suspensão. Segundo Calé, presidente da Associação Nacional de Pós-Graduandos (ANPG), essa suspensão tem consequências negativas imensuráveis, indo da perda do aprimoramento do processo avaliativo e possível apagão de dados sobre a produção científica no Brasil até a perda de credibilidade e da reputação do Sistema Nacional de Pós-graduação, gerando desregulamentação do ensino superior e da pesquisa. ${ }^{12}$

Falando em apagão, voltemos ao CNPq. O Conselho Nacional de Pesquisas (CNPq), hoje chamado de Conselho Nacional de Desenvolvimento Científico e Tecnológico, foi criado em 1951, tendo como objetivo fomentar o desenvolvimento da ciência no país, e está vinculado ao Ministério da Ciência, Tecnologia, Inovações e Comunicações (MCTIC). Tudo, ou quase tudo relacionado, à pesquisa no país passa pelo CNPq, que hospeda plataformas como o Currículo Lattes, que concentra as informações do currículo do pesquisador; plataforma Carlos Chagas, que concentra informações sobre os diversos tipos de bolsas de fomento à pesquisa e o Instituto Brasileiro de Informação, Ciência e Tecnologia (IBICT), que tem como função promoção da popularização da informação científica e tecnológica e que hoje é o único órgão no Brasil para atribuição do código ISSN às revistas científicas. $\frac{13}{}$

Cabe ao CNPq ofertar bolsas de iniciação científica, bolsas para mestrado, doutorado, pós-doutorado, pesquisador visitante, estágio-sênior, bem como bolsas em competições acadêmicas como olimpíadas de matemática para os alunos do ensino fundamental e médio. O foco principal do CNPq é o fomento às pesquisas e favorecer condições financeiras adequadas para que o pesquisador possa desenvolver sua pesquisa.

Diante das analogias tipificadas no início desse texto, o Ministério da Ciência, Tecnologia, Inovações e Comunicações parece ter sido entregue a alguém que não tem muito interesse em defendê-lo e cuidar do desenvolvimento científico e tecnológico no Brasil. Nos últimos 20 anos, a ciência brasileira chegou a ser referência na América Latina. ${ }^{14}$ Segundo estudo do Centro para Ciência e Tecnologia da Universidade de Leiden (Holanda), o Brasil possui 23 centros de pesquisas científicas e 31 universidades que estão entre os principais do mundo, contabilizados no período de 2016-2019. ${ }^{15}$

No entanto, de 2015 até este momento, sucessivos cortes no orçamento do MCTIC e, consequentemente, do CNPq têm acontecido, a ponto de, em 2019, 
a ciência, tecnologia e inovação brasileiras e seus pesquisadores se verem sem recursos para dar continuidade às suas pesquisas porque o MCTIC não tinha como pagar as bolsas de pesquisa, comprometendo as pesquisas de 83 mil bolsistas em todo o país. ${ }^{16}$ Em 2020, tanto a CAPES como o CNPq precisaram de emendas parlamentares devido ao corte sofrido de $40 \%$ na CAPES e de cerca de $87 \%$ para investimentos na infraestrutura, compra de equipamentos e custeio de pesquisas para o CNPq. ${ }^{17}$

Em 2021, a história se repete, e o orçamento destinado à pesquisa, que já era pequeno, diminuiu ainda mais. Houve um corte na proposta orçamentária de $34 \%$, sendo que parte do valor destinado ainda depende de aprovação do congresso nacional para ser liberado, chamado de crédito suplementar.18 Pesquisadores falam em paralisia da ciência brasileira e estado vegetativo. ${ }^{18}$ Em um novo golpe para a pesquisa no Brasil, o Ministério da Economia, por meio do Ofício SEI n438/2021/ME, deliberou pelo corte do crédito suplementar de $\mathrm{R} \$ 690$ milhões - aproximadamente $90 \%$ dos recursos para ciência, tecnologia e inovação. $\frac{19}{} \mathrm{O}$ que significa asfixiar a produção científica brasileira de forma deliberada.

Duas consequências diretas podem ser identificadas devido às ações descritas anteriormente, segundo relatório de ciências da UNESCO 20 : fuga de cérebros, que tem sido realidade para os países em desenvolvimento, como o Brasil; e perda de posições no rank de potências para o desenvolvimento das ciências. Segundo o relatório, os países que investem menos de $1 \%$ do PIB em pesquisas perpetuam sua dependência de tecnologias estrangeiras. Pode-se, ainda, comentar sobre uma terceira consequência que seria a perda da capacidade de produzir e publicar ciência, tecnologia e inovação.

Gostaria, agora, de levá-los (as) à reflexão sobre a importância da pesquisa para a sociedade. Por que pesquisamos tanto?

Ao longo dos anos temos visto o quanto a pesquisa pode ser transformadora quando inserida no contexto social. Foi por meio de pesquisas que se descobriu antibióticos, e essa descoberta revolucionou a sociedade. Foi pelas mãos de pesquisadores que se identificou o HIV-AIDS, que matou milhares de pessoas na década de 80-90. E são tantos, tantos exemplos que demonstram como os resultados de pesquisas nas mais diversas áreas podem melhorar várias dimensões da vida e do viver em sociedade.

E como não falar da pandemia do coronavírus que estamos (ainda!) vivendo? No momento mais crucial, em que a ciência, do mundo e a brasileira, precisa de incentivo para o enfrentamento da Covid-19, o governo, por meio do Ministério da Economia, corta os braços e as pernas do CNPq, que já vinha agonizante, com os sucessivos cortes de verbas. Os países que haviam adotado o estado mínimo em suas gestões voltaram atrás no período da pandemia e investiram na ciência, na saúde, no fortalecimento das redes de proteção social e na criação de pacotes fiscais emergenciais para o enfrentamento da Covid19, mesmo que para isso tenham ultrapassado o teto dos gastos do planejamento orçamentário. 11

E o Brasil, na contramão do mundo, como parece ser a especialidade do governo federal, insiste em manter o teto de gastos, às custas de mais de 600 mil mortes por Covid-19, 13 milhões de desempregados, uma parcela mínima recebendo um auxílio de $\mathrm{R} \$ 150,00$ em média, que não compra, hoje, nem um botijão de gás, na maioria dos estados. Contabilizamos mais de 19 milhões de pessoas vivendo em insegurança alimentar devido à pandemia.

Se o fundamental da pesquisa é transformar as condições de vida de uma sociedade, porque o governo investirá em pesquisa, se esse mesmo governo nos demonstra todos os dias que estamos vivendo um processo de dizimação da população brasileira?

Apesar disso, avisamos a quem interessar possa: enquanto houver pessoas curiosas e desejosas de viver em um mundo melhor, pesquisadores serão formados e pesquisas serão publicadas. E cada novo estudo será um ato de resistência. Esse governo vai passar. E estaremos aqui para reconstruir este país.

\section{Conflitos de interesses}

Nenhum conflito financeiro, legal ou político envolvendo terceiros (governo, empresas e fundações privadas, etc.) foi declarado para nenhum aspecto do trabalho submetido (incluindo, mas não se limitando a subvenções e financiamentos, participação em conselho consultivo, desenho de estudo, preparação de manuscrito, análise estatística, etc.). 


\section{Referências}

1. Gortázar NG, Alessi G. Investigado, Ricardo Salles, deixa comando do meio ambiente em meio a desmatamento recorde [Internet]. El País. 2021 [citado em 2021 out 09]. Disponível em: https://brasil.elpais.com/brasil/2021-06-23/investigadoricardo-salles-deixa-comando-do-meio-ambiente-em-meio-adesmatamento-recorde.html

2. Zinet C. Corte no orçamento da educação em 2016 será superior ao deste ano [Internet]. Educação Integral. 2015 [citado em 2021 out 09]. Disponível em: https://educacaointegral.org. br/reportagens/corte-orcamento-da-educacao-em-2016-serasuperior-ao-desse-ano/

3. Betim F. Corte de quase metade das verbas em ciência compromete pesquisas de zika até câncer [Internet]. El País. 2017 [citado em 2021 out 09]. Disponível em: https://brasil.elpais.com/ brasil/2017/11/27/ciencia/1511806311 065202.html

4. Dotta R, Tatemoto R. Cortes na educação ameaça $80 \%$ das pesquisas do país [Internet]. Brasil de Fato. 2018 [citado em 2021 out 09]. Disponível em: https://www.brasildefatomg.com.br/2018/08/14/ corte-na-educacao-ameaca-80-das-pesquisas-do-pais

5. Tenente L, Figueiredo P. Entenda o corte de verba das universidades federais e saiba como são os orçamentos das 10 maiores [Internet]. g1. 2019 [citado em 2021 out 09]. Disponível em: https://g1.globo.com/educacao/noticia/2019/05/15/entendao-corte-de-verba-das-universidades-federais-e-saiba-como-saoos-orcamentos-das-10-maiores.ghtml

6. Westin R. Corte de verbas da ciência prejudica reação à pandemia e desenvolvimento do país [Internet]. Agência Senado. 2020 [citado em 2021 out 09]. Disponível em: https://www12. senado.leg.br/noticias/infomaterias/2020/09/corte-de-verbas-daciencia-prejudica-reacao-a-pandemia-e-desenvolvimento-do-pais

7. Pires B. Ciência brasileira sofre com cortes de verbas e encara cenário dramático para pesquisa em 2021 [Internet]. El País. 2020 [citado em 2021 out 09]. Disponível em: https://brasil.elpais.com/ brasil/2020-12-31/ciencia-brasileira-sofre-com-cortes-de-verbas-eencara-cenario-dramatico-para-pesquisas-em-2021.html

8. Sociedade Brasileira de Física. Nota em defesa da CAPES [Internet]. SBF. 2021 [citado em 2021 out 09]. Disponível em: http://www.sbfisica.org.br/v1/home/index.php/pt/acontece/1305nota-em-defesa-da-capes

9. Mendes L. Presidente da Capes nomeia orientanda para cargo de diretora internacional [Internet]. Poder360. 2021 [citado em 2021 out 09]. Disponível em: https://www.poder360.com.br/ governo/presidente-da-capes-nomeia-orientanda-para-cargo-dediretora-internacional/

10. Biernath $A$. O que se sabe do 'apagão do CNPq' que deixou cientistas sem acesso ao currículo Lattes [Internet]. BBC. 2021 [citado em 2021 out 09]. Disponível em: https://www.bbc.com/ portuguese/brasil-57992217
11. Blasi BGD. Apagão do CNPq: falha técnica causou queda de Lattes e outros sistemas [Internet]. Tecnoblog. 2021 [citado em 2021 out 09]. Disponível em: https://tecnoblog.net/468394/apagaodo-cnpq-falha-tecnica-causou-queda-de-lattes-e-outros-sistemas/

12. Calé F. A quem interessa a paralisação do Sistema de Avaliação da CAPES? [Internet]. Jornal da USP. 2021 [citado em 2021 out 09]. Disponível em: https://jornal.usp.br/artigos/a-queminteressa-a-paralisacao-do-sistema-de-avaliacao-da-capes/

13. Ministério da Ciência Tecnologia e Inovações, Instituto Brasileiro de Informação em Ciência e Tecnologia. Histórico [Internet]. Ministério da Ciência, Tecnologia e Inovações; 2021 [citado em 2021 out 10]. Disponível em: https://www.gov.br/ibict/ pt-br/acesso-a-informacao/sobre-o-ibict-1/historico

14. Fórum nacional de pró-reitores de pesquisa e pós-graduação. Nota Técnica ao Parlamento Brasileiro: Cortes Orçamentários [Internet]. Brasília: FOPROP; 2021. Disponível em: http://www. foprop.org.br/uploads/downloads/2021_10_11/Nota-Tecnica-aoParlamento-Brasileiro-Cortes-Orcamentarios_retificada.pdf

15. Centre of Science and Technology Studies. CWTS Leiden Ranking 2021 [Internet]. Leiden University. 2021. Disponível em: https://www.leidenranking.com/ranking/2021/list

16. Redação Senado Notícias. Remanejamento só garante pagamento de bolsas do CNPq do mês de setembro [Internet]. Senado Notícias. 2021 [citado em 2021 out 10]. Disponível em: https://www12.senado.leg.br/noticias/materias/2019/09/05/ remanejamento-so-garante-pagamento-de-bolsas-do-cnpq-domes-de-setembro

17. Machado R. CAPES e CNPq dependem de emendas parlamentares para recompor verbas em 2020 [Internet]. Câmara dos deputados. 2019 [citado em 2021 out 10]. Disponível em: https:// www.camara.leg.br/noticias/607478-capes-e-cnpq-dependem-deemendas-parlamentares-para-recompor-verbas-em-2020/

18. Escobar H. Orçamento 2021 condena ciência brasileira a "estado vegetativo" [Internet]. 2020 [citado em 2021 out 10]. Disponível em: https://jornal.usp.br/universidade/politicas-cientificas/orcamento2021-coloca-ciencia-brasileira-em-estado-vegetativo/

19. Yahoo!notícias. Ministério da Economia vai cortar mais de 90\% de verbas destinadas para a ciência [Internet]. Yahoo. 2021. Disponível em: https://br.noticias.yahoo.com/ministerioda-economia-vai-cortar-mais-de-90-verbas-destinadas-para-aciencia-113811726.html

20. Schneegans S, Lewis J, Straza T, editores. Relatório de Ciências da UNESCO: A corrida contra o tempo por um desenvolvimento mais inteligente - Resumo executivo e cenário brasileiro [Internet]. Paris: UNESCO; 2021. Disponível em: https://unesdoc. unesco.org/ark:/48223/pf0000377250 por

21. Barría C. Coronavírus: os 10 países que mais gastaram para enfrentar a pandemia de covid-19 [Internet]. BBC News. 2020. Disponível em: https://www.bbc.com/portuguese/ internacional-52721417 